\title{
Superior mesenteric artery blood flow velocity in necrotising enterocolitis
}

Children Nationwide Neonatal Centre King's College Hospital School of Medicine, London S T Kempley H R Gamsu

Correspondence to: Dr S T Kempley Frederick Still Ward, King's College Hospital, London SE5 9RS.

Accepted 9 March 1992

\author{
S T Kempley, H R Gamsu
}

\begin{abstract}
Doppler measurements of blood flow velocity were obtained from the superior mesenteric artery (SMA), coeliac axis, and anterior cerebral artery (ACA) of 19 infants with suspected necrotising enterocolitis, which was classified as confirmed $(n=9)$ or unconfirmed $(n=8)$. Infants with confirmed disease were compared with controls who were either enterally fed or who were receiving intravenous fluids.
\end{abstract}

SMA velocity was significantly higher in the infants with confirmed necrotising enterocolitis $(36.5 \mathrm{~cm} / \mathrm{s})$ than in unfed controls $(20.4 \mathrm{~cm} / \mathrm{s})$ or infants with unconfirmed enterocolitis $(19.6 \mathrm{~cm} / \mathrm{s})$.

Three infants with confirmed disease had data from before the onset of symptoms. One had low SMA velocity on the first day of life, and one showed no increase in SMA velocity after enteral feeds were started.

SMA velocity is increased when infants develop symptoms of necrotising enterocolitis, suggesting that total gut ischaemia is not present at the time that the disease is clinically apparent, although it may precede the onset of symptoms and play a part in the pathogenesis of the disorder.

Epidemiological studies have suggested a bewildering variety of risk factors for necrotising enterocolitis. Identified risk factors include birth asphyxia, ${ }^{1-4}$ chronic intrauterine hypoxia, ${ }^{56}$ apnoea, ${ }^{2} 478$ umbilical catheterisation, ${ }^{1} 479$ respiratory distress and ventilation, ${ }^{4} 78$ patent ductus arteriosus, ${ }^{3}$ polycythaemia, ${ }^{8} 10$ hypoglycaemia, ${ }^{8}$ and hypothermia. ${ }^{10}$ It is widely believed that intestinal ischaemia is the unifying mechanism that explains the ability of these many different factors to injure the neonatal bowel. Risk factors might cause ischaemia directly or as a consequence of the 'diving reflex' when blood flow is diverted from the abdominal organs during hypoxia, thus preserving cerebral oxygenation.

However, the concept of necrotising enterocolitis being predisposed to by gut ischaemia is not straightforward. Clustering of cases has been used to support the idea of an infective aetiology. ${ }^{11}$ Although many agents, including bacteria and viruses, have been implicated in some outbreaks, ${ }^{12}$ other studies have not identified infective agents to be consistently associated with necrotising enterocolitis. ${ }^{7}$ It has also been proposed that mucosal immaturity alone may be the most important factor in its aetiology. ${ }^{13} 14$ The fact that necrotising enterocolitis is rare in the absence of enteral feeding demonstrates the importance of intraluminal factors. Breast milk exerts a protective effect whereas hyperosmolar feeds, ${ }^{2}$ or hyperosmolar drugs such as high doses of vitamin $\mathrm{E},{ }^{15}$ may be risk factors.

In order to examine the hypothesis that necrotising enterocolitis is due to intestinal ischaemia, Doppler ultrasound has recently been used to study the characteristics of blood flow in the superior mesenteric artery of infants in high risk groups. We have demonstrated a specific reduction in superior mesenteric artery (SMA) blood flow velocity in infants who are small for gestational age, who experienced chronic intrauterine hypoxia ${ }^{16}$; and Coombs et al have shown absent diastolic flow and reduced velocity in infants with patent ductus arteriosus. ${ }^{17}$ However, none of the infants in these studies went on to develop necrotising enterocolitis.

We therefore set out to measure SMA blood flow velocity using Doppler ultrasound in infants who developed necrotising enterocolitis. By studying from birth a large number of infants who were at risk we also hoped to have data that preceded the onset of this condition in a number of infants. In order to document the specificity of our findings for the mesenteric circulation, we also measured velocity in the coeliac axis and anterior cerebral artery (ACA).

\section{Methods}

SUBJECTS WITH NECROTISING ENTEROCOLITIS The criteria of the British Association of Perinatal Medicine (BAPM) were used to define casès of suspected necrotising enterocolitis which occurred on our unit over a two year period. ${ }^{18}$

A total of 19 infants were studied. To be classified as a case of suspected necrotising enterocolitis an infant must have had at least two of the following features: abdominal distension, blood in the faeces, a distinct clinical deterioration (hypotonia, lethargy, or apnoea), or increased intraluminal gas visible on an abdominal radiography. The characteristics of these infants are shown in table 1.

\section{Confirmed cases}

Nine infants were subsequently confirmed to have necrotising enterocolitis on the basis of radiological findings (intramural gas, hepatic portal venous gas), surgery or postmortem 
Table 1 Characteristics of the infants with suspected necrotising enterocoliti

\begin{tabular}{|c|c|c|c|c|c|c|c|}
\hline \multirow[t]{2}{*}{ Cases } & \multirow[t]{2}{*}{ Sex } & \multirow[t]{2}{*}{$\begin{array}{l}\text { Gestation } \\
\text { (weeks) }\end{array}$} & \multirow[t]{2}{*}{$\begin{array}{l}\text { Birth weight } \\
(\mathrm{kg})\end{array}$} & \multirow{2}{*}{$\begin{array}{l}\text { Postnatal } \\
\text { age } \\
\text { (days) }\end{array}$} & \multirow{2}{*}{$\begin{array}{l}\text { Mean blood } \\
\text { pressure } \\
(\mathrm{mm} \mathrm{Hg})\end{array}$} & \multicolumn{2}{|c|}{$\begin{array}{l}\text { Last enteral } \\
\text { feedt }\end{array}$} \\
\hline & & & & & & $\begin{array}{l}\text { Hours } \\
\text { before }\end{array}$ & $\%$ intake \\
\hline \multicolumn{8}{|c|}{ Confirmed cases: } \\
\hline 1 & $\mathrm{~F}$ & 24 & 762 & 12 & 29 & - & - \\
\hline 2 & $\mathrm{~F}$ & 26 & 902 & 25 & 51 & 1 & 100 \\
\hline 3 & $\mathbf{M}$ & 28 & 1248 & 6 & 46 & 15 & 100 \\
\hline 4 & $\mathrm{~F}$ & 28 & 1436 & 10 & 46 & 85 & 100 \\
\hline 5 & $\mathrm{~F}$ & 29 & 1150 & 8 & 19 & - & - \\
\hline 6 & $\mathbf{F}$ & 30 & $1040 *$ & 44 & 64 & 30 & 100 \\
\hline 7 & $\mathrm{~F}$ & 34 & $1220^{*}$ & 6 & - & 24 & 100 \\
\hline 8 & $\mathbf{F}$ & 36 & 2990 & 22 & 63 & 28 & 100 \\
\hline 9 & $\mathbf{M}$ & 39 & 3180 & 1 & - & 8 & 100 \\
\hline Mean & & $30 \cdot 4$ & 1550 & 15 & $45 \cdot 4$ & & \\
\hline SD & & 4.9 & 890 & 13.4 & $16 \cdot 6$ & & \\
\hline \multicolumn{8}{|c|}{ Suspected, unconfirmed cases: } \\
\hline 10 & $\vec{M}$ & 23 & 510 & 8 & 28 & - & - \\
\hline 11 & $\mathbf{F}$ & 24 & 680 & 14 & 60 & - & - \\
\hline 12 & $\mathbf{F}$ & 24 & 720 & 26 & 36 & 32 & 100 \\
\hline 13 & $\mathbf{M}$ & 26 & 920 & 14 & 34 & - & - \\
\hline 14 & $\mathbf{M}$ & 28 & 1246 & 6 & 43 & - & - \\
\hline 15 & $\mathbf{F}$ & 29 & $516 * *$ & 9 & - & 40 & 50 \\
\hline 16 & $\mathbf{F}$ & 32 & $666 * *$ & 26 & - & 79 & 100 \\
\hline 17 & $\mathbf{M}$ & 32 & $1180^{* *}$ & 12 & 66 & - & - \\
\hline Mean & & $27 \cdot 3$ & 810 & 14 & $\mathbf{4 4 \cdot 4}$ & & \\
\hline SD & & 3.6 & 280 & $7 \cdot 8$ & $15 \cdot 2$ & & \\
\hline \multicolumn{8}{|c|}{ Cases with other pathology: } \\
\hline 18 & $\mathbf{M}$ & 27 & 1118 & 18 & 44 & 26 & 100 \\
\hline 19 & $M$ & 28 & 1100 & 12 & 30 & 13 & 43 \\
\hline
\end{tabular}

Infants who were small for gestational age are indicated: * birth weight $<10$ th centile for gestation; ${ }^{* *}<3$ rd centile. See text for further details. + Where no figure given, the infant had no enteral feeds. findings, in accordance with the BAPM criteria. One infant (case 3) was a surviving twin whose cotwin was a miscarriage some weeks before delivery. Another (case 8) was born with a diaphragmatic hernia, which had been surgically repaired on the first day of life. There was a term infant (case 9) whose mother had admitted to abusing a number of drugs during pregnancy. Only one infant (case 1) had an umbilical arterial catheter in place at the time of measurement, and only two had positive blood cultures (case 1, Candida albicans; case 7, Staphylococcus aureus).

Cases with other abdominal pathology

Two infants had proved intra-abdominal

Table 2 Characteristics of the control infants

\begin{tabular}{|c|c|c|c|c|}
\hline Controls & $\begin{array}{l}\text { Gestation } \\
\text { (weeks) }\end{array}$ & $\begin{array}{l}\text { Birth weight } \\
(g)\end{array}$ & $\begin{array}{l}\text { Postnatal } \\
\text { age } \\
\text { (days) }\end{array}$ & $\begin{array}{l}\text { Mean blood } \\
\text { pressure } \\
\text { (mm Hg) }\end{array}$ \\
\hline \multicolumn{5}{|c|}{ Controls on } \\
\hline 1 & 25 & 768 & 7 & 36 \\
\hline 2 & 26 & 910 & 9 & 53 \\
\hline 3 & 28 & 1164 & 9 & - \\
\hline 4 & 29 & 1510 & 11 & 57 \\
\hline 5 & 30 & 1300 & 9 & - \\
\hline 6 & 30 & $1026 *$ & 7 & 45 \\
\hline 7 & 34 & $1260^{* *}$ & 7 & - \\
\hline 8 & 40 & 3482 & 5 & 60 \\
\hline 9 & 42 & 3482 & 2 & \\
\hline Mean & $31 \cdot 6$ & 1656 & $7 \cdot 3$ & $50 \cdot 2$ \\
\hline SD & $6 \cdot 0$ & 106 & $2 \cdot 6$ & 9.7 \\
\hline \multicolumn{5}{|c|}{$\begin{array}{l}\text { Enterally fed } \\
\text { controls: }\end{array}$} \\
\hline 1 & 25 & 870 & 13 & - \\
\hline 2 & 26 & 966 & 28 & - \\
\hline 3 & 27 & 942 & 16 & - \\
\hline 4 & 28 & 1038 & 7 & - \\
\hline 5 & 30 & 1506 & 8 & - \\
\hline 6 & 30 & $946^{*}$ & 8 & - \\
\hline 7 & 36 & $1798^{* *}$ & 9 & - \\
\hline 8 & 34 & 1980 & 14 & 56 \\
\hline 9 & 41 & 3910 & 1 & - \\
\hline Mean & $30 \cdot 8$ & 1500 & 12 & \\
\hline SD & $5 \cdot 3$ & 980 & $7 \cdot 6$ & \\
\hline
\end{tabular}

Infants who were small for gestational age are indicated: *birth weight $<10$ th centile for gestation; $* *<3$ rd centile. pathology other than necrotising enterocolitis: one was found to have an ileal perforation in association with a meconium plug, and the other had intestinal infarction from an aortic thrombus, obstructing the coeliac and mesenteric arteries. (These two constitute the 'other abdominal pathology' group.)

Suspected, unconfirmed cases

Of the remaining eight infants, six were found to be septicaemic (case 10, $C$ albicans; cases 11 and 15, Klebsiella sp, cases 12 and 17, Staphylococcus epidermidis; case 13, enterobacter), one was severely growth retarded and thought to have meconium plugging, and in one the cause of his deterioration was not identified.

Mean birth weight was significantly lower in the group with unconfirmed necrotising enterocolitis, with three having a birth weight less than the third centile for gestation.

\section{CONTROLS}

For each infant with confirmed necrotising enterocolitis, control data were selected from Doppler measurements performed on babies enrolled in other studies, who had not suffered from gastrointestinal problems or birth asphyxia. Data from a pool of 80 infants were available for matching. Control data were matched for postnatal age, the birth weight and gestation of the infant, and the degree of intrauterine growth retardation. For each index case we selected one control who was receiving enteral feeds, and one who was receiving intravenous fluids only, giving two control groups. The characteristics of the control infants are shown in table 2.

\section{MEASUREMENTS}

Measurements of blood flow velocity and pulsatility index were obtained from the SMA, coeliac axis, and ACA as previously described. ${ }^{16}$ The artery was visualised in real time and range-gating used to sample pulsed wave Doppler signals from the particular artery under study. All readings were corrected for the angle of insonation. The measurements were obtained after the onset of symptoms during the acute phase of the illness.

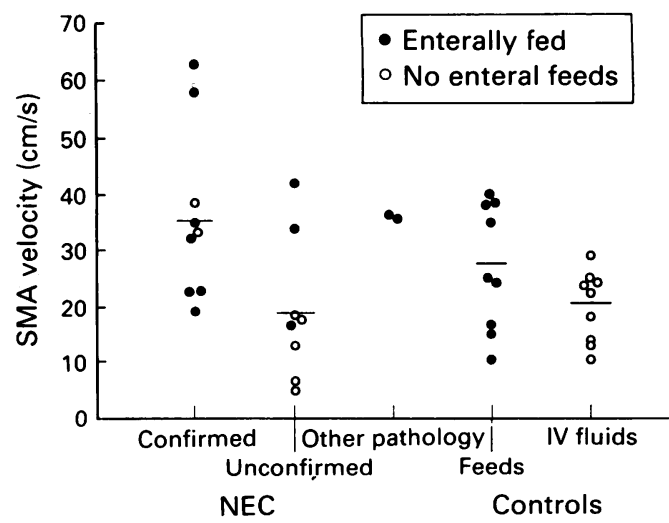

Figure 1 Blood flow velocity in the SMA for individual infants with suspected necrotising enterocolitis (NEC), and for infants in the control groups, receiving enteral feeds or intravenous (IV) fluids. 
Table 3 Mean (SD) of velocity and pulsatility index in the SMA, coeliac axis, and $A C A$ for the main groups

\begin{tabular}{|c|c|c|c|c|c|c|}
\hline & \multicolumn{3}{|c|}{ Velocity $(\mathrm{cm} / \mathrm{s})$} & \multicolumn{3}{|c|}{ Pulsatility index } \\
\hline & $S M A$ & $\begin{array}{l}\text { Coeliac } \\
\text { axis }\end{array}$ & $A C A$ & $S M A$ & $\begin{array}{l}\text { Coeliac } \\
\text { axis }\end{array}$ & $A C A$ \\
\hline $\begin{array}{l}\text { NEC: } \\
\text { confirmed }\end{array}$ & $\begin{array}{l}36 \cdot 5 \\
(15 \cdot 3)\end{array}$ & $\begin{array}{l}39 \cdot 9 \\
(9 \cdot 8)\end{array}$ & $\begin{array}{l}19 \cdot 1 \\
(9 \cdot 2)\end{array}$ & $\begin{array}{l}2 \cdot 17 \\
(0 \cdot 9)\end{array}$ & $\begin{array}{l}1.58 \\
(0.5)\end{array}$ & $\begin{array}{l}2 \cdot 20 \\
(2 \cdot 4)\end{array}$ \\
\hline $\begin{array}{l}\text { NEC: suspected, } \\
\text { unconfirmed }\end{array}$ & $\begin{array}{l}19 \cdot 6^{*} \\
(12 \cdot 9)\end{array}$ & $\begin{array}{l}33 \cdot 1 \\
(15 \cdot 4)\end{array}$ & $\begin{array}{l}19 \cdot 3 \\
(9 \cdot 0)\end{array}$ & $\begin{array}{l}2 \cdot 99 \\
(1 \cdot 7)\end{array}$ & $\begin{array}{l}1 \cdot 69 \\
(1 \cdot 1)\end{array}$ & $\begin{array}{l}1.67 \\
(0.8)\end{array}$ \\
\hline $\begin{array}{l}\text { Controls: } \\
\text { enterally fed }\end{array}$ & $\begin{array}{l}27 \cdot 4 \\
(11 \cdot 2)\end{array}$ & $\begin{array}{l}36 \cdot 5 \\
(14 \cdot 0)\end{array}$ & $\begin{array}{l}19 \cdot 7 \\
(6 \cdot 4)\end{array}$ & $\begin{array}{l}2.56 \\
(0.9)\end{array}$ & $\begin{array}{l}1.75 \\
(0.8)\end{array}$ & $\begin{array}{l}1.64 \\
(0.5)\end{array}$ \\
\hline $\begin{array}{l}\text { Controls: on } \\
\text { IV fluids }\end{array}$ & $\begin{array}{l}20 \cdot 4^{* * *} \\
(6 \cdot 4)\end{array}$ & $\begin{array}{l}38 \cdot 5 \\
(15 \cdot 3)\end{array}$ & $\begin{array}{l}19 \cdot 8 \\
(2 \cdot 3)\end{array}$ & $\begin{array}{l}2 \cdot 72 \\
(1 \cdot 0)\end{array}$ & $\begin{array}{l}1.39 \\
(0 \cdot 5)\end{array}$ & $\begin{array}{l}1.36 \\
(0.4)\end{array}$ \\
\hline $\begin{array}{l}\text { Controls: } \\
\text { combined }\end{array}$ & $\begin{array}{l}23 \cdot 9 \\
(9 \cdot 3)\end{array}$ & & & & & \\
\hline
\end{tabular}

Significant differences between the confirmed necrotising enterocolitis (NEC) group and the other groups are shown $(*=p<0.05 ; * *=p<0.01)$

IV, intravenous.

Data from the infants with confirmed necrotising enterocolitis were compared with the data from the other groups using unpaired $t$ tests. Variance ratios (F) were used to compare the variances of cerebral artery velocities.

\section{Results}

DATA AT THE TIME OF SYMPTOMS

Mean SMA velocity was significantly higher in the infants with confirmed necrotising enterocolitis $(36.5 \mathrm{~cm} / \mathrm{s})$ than in infants with suspected, unconfirmed disease $(19.6 \mathrm{~cm} / \mathrm{s}$, $\mathrm{p}<0.05$; fig 1 , table 3 ). SMA velocity was also significantly higher in the confirmed group than in the control group receiving intravenous fluids $(20.4 \mathrm{~cm} / \mathrm{s}, \mathrm{p}<0.05)$. Although mean SMA velocity was slightly higher in infants with confirmed disease than in the control group receiving enteral feeds $(27.4 \mathrm{~cm} / \mathrm{s})$, this difference was not significant.

When the two control groups were combined, SMA velocity was still significantly lower in these infants than in infants with confirmed necrotising enterocolitis $(p<0 \cdot 05)$.

There were no significant differences between the groups in mean coeliac or cerebral artery velocities. However, there was a much greater variation in cerebral artery velocity in the groups of infants with confirmed and suspected necrotising enterocolitis compared with the group of controls on intravenous fluids (confirmed: $F=15.9, \mathrm{p}<0.001$; unconfirmed: $F=15 \cdot 2, \mathrm{p}<0 \cdot 001$ ).

There were no statistically significant differences in pulsatility index between the groups.

\section{PROSPECTIVE DATA}

Prospective data obtained from three infants with confirmed necrotising enterocolitis is shown in fig 2. The first of these (case 2) had only one measurement performed, some time before the onset of necrotising enterocolitis. SMA velocity was normal at this stage.

The second infant (case 3 ) was the survivor of a twin pregnancy where the other twin was a miscarriage. SMA velocity was initially normal but did not increase after the introduction of enteral feeding at 3 days of age. When he developed necrotising enterocolitis at 6 days the SMA velocity was very high. After treatment this returned to normal, and when feeds were recommenced there was an increase in SMA velocity.
The third infant (case 7) was growth retarded and had a very low SMA velocity on day 1 (the lowest day 1 value we have obtained from a very low birthweight infant). This rose to a normal value by day 3,24 hours after the introduction of enteral feeds. On day 6, when she developed necrotising enterocolitis, the SMA velocity stayed at a relatively high level even after feeds were stopped.

Prospective data were also obtained from four infants with suspected, unconfirmed necrotising enterocolitis. In two infants the values were normal (cases 10 and 14), in one there was no increase in SMA velocity when feeds were introduced (case 15) and in one there was a low SMA velocity on day 1 (case 16).

\section{Discussion}

By the time that symptoms were apparent, SMA blood flow velocity was significantly higher in infants with confirmed necrotising enterocolitis than in unfed controls. SMA velocity was also higher in confirmed cases than in infants with suspected but unconfirmed disease. Mean SMA velocity was slightly (but not significantly) higher in the infants with necrotising enterocolitis than in controls receiving enteral feeds.

There are a number of possible explanations for the differences in velocity between confirmed and suspected cases. There were
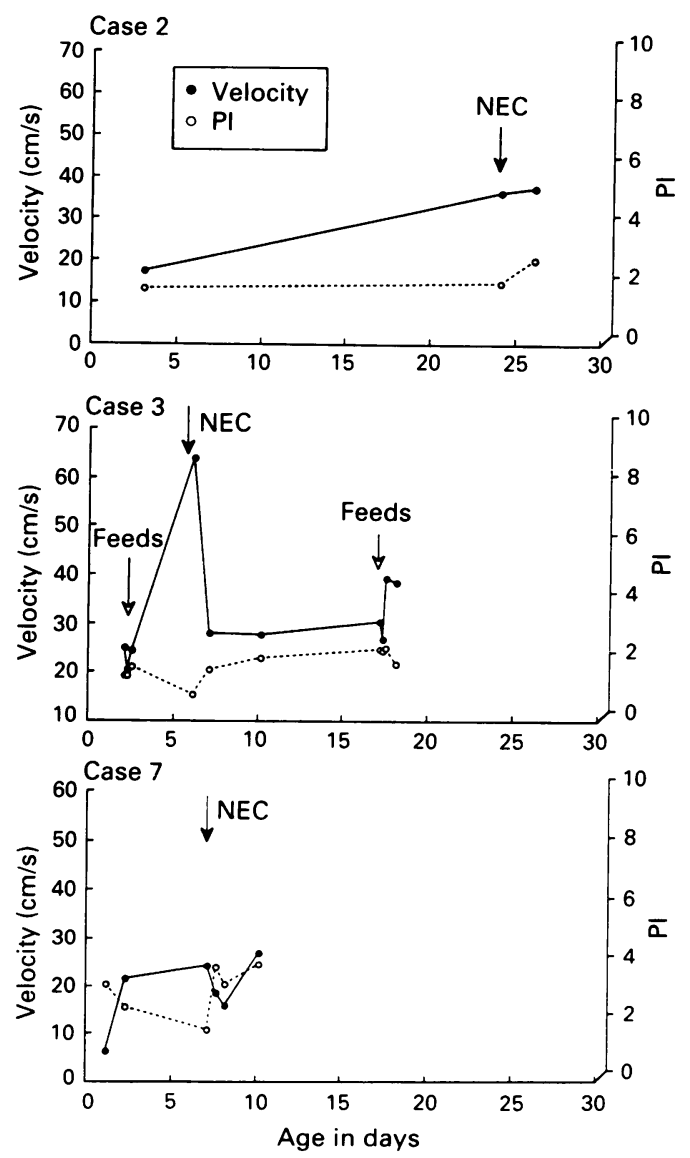

Figure 2 Blood flow velocity and pulsatility index (PI) from the SMA of the three infants with confirmed necrotising enterocolitis (NEC) who had prospective data. 
more infants who were small for gestational age in the unconfirmed group. We have previously demonstrated growth retardation to be associated with lower SMA velocity. ${ }^{16}$ Fewer of the unconfirmed group had received enteral feeds at any stage in their life, and enteral feeding has been shown to increase SMA velocity even in premature infants. ${ }^{19} 20$ More were septicaemic, and these findings may represent the effect of septicaemia on SMA velocity. Finally, there may be a raised SMA blood flow velocity in the infants with confirmed necrotising enterocolitis, but not in those with unconfirmed disease, because the disorders are unrelated.

Were infants who were not receiving enteral feeds appropriate controls for the infants with necrotising enterocolitis? None of the index cases was receiving enteral feeds at the time that the measurements were made, and all had their stomachs aspirated via a nasogastric tube. Two had never received any feeds enterally, but in the other seven the time elapsed since the last feed varied between 1 and 85 hours. Infants whose feeds had been stopped would have been expected to have had gastrointestinal blood flow velocity somewhere between the levels found in fed and unfed infants, but it is not known how quickly or to what extent blood flow decreases after stopping feeds. Even when the two control groups were combined, velocity was significantly higher in the infants with confirmed necrotising enterocolitis. Although previous enteral feeding may account for some of the observed increase in SMA velocity, it would not account for it all.

Why should necrotising enterocolitis produce an increase in SMA velocity? If a baby is operated upon, the serosal surface of unaffected bowel is often noticed to be inflamed; the increased SMA velocity in necrotising enterocolitis could therefore result from an inflammatory response in the remaining 'healthy' bowel. Prospective data showed a very low SMA velocity in one infant (case 7) five days before the onset of symptoms. It is possible that an ischaemic insult to the gut may precede the onset of necrotising enterocolitis, with the increase in SMA velocities at the time of clinical presentation representing a postischaemic hyperaemia. A reduction of vessel diameter could produce an increase in velocity without any increase in volume flow, but using ultrasound imaging we saw no evidence of arterial thrombosis in any of the infants with confirmed disease, and only one of these infants still had an umbilical catheter in place. All measurements were taken from the SMA close to its origin from the aorta, a location where active changes in vascular diameter are unlikely.

Data showing a low SMA velocity, or a lack of response to enteral feeding, before the onset of necrotising enterocolitis may indicate a mechanism predisposing to this condition. However, both of these findings were also noted in growth retarded infants who had suspected but unconfirmed disease. Clearly there must be other factors operating which determine which infants will develop confirmed disease.

There was a significantly greater variation in cerebral artery velocities in both of the necrotising enterocolitis groups, compared with the controls, although there was no difference in mean velocity. The diversion of cardiac output into a mesenteric circulation which has a fixed high blood flow might disturb the regulation of blood pressure and cerebral blood flow.

SMA blood flow velocity is probably increased, and certainly not reduced, at the time infants develop necrotising enterocolitis. It is therefore unlikely that an overall reduction in gut blood flow is responsible for the progression of the disease, although localised factors may affect discrete areas of bowel. However, low total gut blood flow may have a causative role early in the pathogenesis of the disease, before any symptoms develop.

1 Bunton GL, Durbin GM, McIntosh N, et al. Necrotising enterocolitis. Arch Dis Child 1977;52:772-7.

2 Yu VYH, Tudehope DI. Neonatal necrotising enterocolitis: perinatal risk factors. Med $\mathcal{F}$ Aust 1977;i:688-93.

3 Ryder RW, Shelton JD, Guinan ME. Necrotising enterocolitis: a prospective multicentre investigation. $A m \boldsymbol{f}$ Epidemiol 1980;112:113-23.

4 Palmer SR, Thomas SSJ, Cooke RWI, et al. Birthweight specific risk factors for necrotising enterocolitis. $\mathfrak{f}$ Epidemiol Community Health 1987;41:210-4.

5 Hackett GA, Campbell S, Gamsu H, Cohen-Overbeek T, Pearce JMF. Doppler studies in the growth retarded foetus and prediction of neonatal necrotising enterocolitis, haemorrhage and neonatal morbidity. $B M F$ 1987;294: 13-6.

6 Malcoim G, Ellwood D, Devonald K, Beilby R, Henderson-Smart D. Absent or reversed end diastolic end flow velocity in the umbilical artery and necrotising enteroocolitis. Arch Dis Child 1991;66:805-7.

7 Smith MF, Borriello SP, Clayden GS, Casewell MW. Clinical and bacteriological findings in necrotising enterocolitis: a controlled study. $\mathcal{f}$ Infect $1980 ; 2: 23-31$.

8 Wilson R, Delportillo M, Schmidt E, Feldman RA, Kanto WP. Risk factors for necrotising enterocolitis in infants weighing more than 2000 grams at birth: a case control weighing more than 2000 grams

9 Frantz ID, L'Heureux PL, Engel RR, Hunt CE. Frantz ID, L'Heureux PL, Engel RR, Hunt

10 Yu VYH, Joseph R, Bajukk B, Orgill A, Astbury J. Perinatal risk factors for necrotising enterocolitis. Arch Dis Child 1984;59:430-4.

11 Book LS, Overall JC, Herbst J, Britt MR, Epstein B, Jung AL. Clustering of necrotizing enterocolitis. $N$ Engl $f$ Med 1977;297:984-6.

12 Han VKM, Sayed H, Chance GW, Brabyn DG, Shaheed W. An outbreak of Clostridium difficile necrotizing enterocolitis: a case for oral vancomycin therapy. Pediatrics 1983;71:935-41.

13 Wilson R, Kanto WP, McCarthy BJ, Burton A, Lewin P, Feldman RA. Age at onset of necrotising enterocolitis: an epidemiologic analysis. Pediatr Res 1982;16:82-4.

14 Kanto WP, Wilson R, Breart GL, et al. Perinatal events and necrotizing enterocolitis in premature infants. $A m \mathcal{F}$ ais Child 1987;141:167-9.

15 Finer NN, Peters KL, Hayek Z, Merkel CL. Vitamin E and necrotising enterocolitis. Pediatrics 1984;73:387-93. and necrotising enterocolitis. Pediatrics 1984;73:387-93.
Kempley ST, Gamsu HR, Vyas S, Nicolaides K. Effects of Kempley ST, Gamsu HR, Vyas S, Nicolaides K. Effects of cerebral blood flow velocity. Arch Dis Child 1991; 65:115-8.

17 Coombs RC, Morgan MEI, Durbin GM, Booth IW, McNeish AS. Gut blood flow velocities in the newborn: effects of patent ductus arteriosus and parenteral indomethacin. Arch Dis Child 1990;65:67-71.

18 British Association for Perinatal Paediatrics and Public Health Laboratory Service CDSC. Surveillance of necrotising enterocolitis 1981-2. BMF 1983;287:824-6.

9 Leidig E. Doppler analysis of superior mesenteric artery blood flow in preterm infants. Arch Dis Child 1989;64:476-80.

20 Gladman G, Sims DG, Chiswick ML. Gastrointestinal blood flow velocity after the first feed. Arch Dis Child 1991;66:17-20. 